\section{NEOPLASTIC ANGIOENDOTHELIOMATOSIS INVOLVING THE CENTRAL NERVOUS SYSTEM}

\section{To the Editor}

The recent case of neoplastic angioendotheliomatosis (NAE) involving the CNS reported by Shuaib and Murphy ${ }^{1}$ prompted us to review two of our patients who also presented with steadily progressive neurological deterioration of uncertain etiology. Both were eventually diagnosed at autopsy as having CNS angioendotheliomatosis. These cases illustrate further the protean manifestations of NAE and emphasize the need for a raised level of clinical awareness of this unusual entity, particularly in cases of non-specific neurological deterioration of recent onset. The plethora of recent cases reported in the literature suggest that the actual incidence of NAE is probably far higher than was originally thought. ${ }^{1-5}$

Case 1 An 86 year old woman. who had been recently quite well, presented with a one month history of increasing weakness with anorexia, a 30 pound weight loss and decreasing mental alertness. Her past history included congestive cardiac failure, myocardial infarction and pacemaker insertion for complete heart block. On physical examination she appeared drowsy and slow to respond to commands but had no localizing neurological signs. Further examination and laboratory tests were non-contributory. During her 5 week stay in hospital her mental status steadily deteriorated with increasing unresponsiveness prior to death. Her clinical diagnosis was of dementia with terminal bronchopneumonia.

Case 2 A 54 year old previously well man was admitted to hospital with several months of progressive weakness of the lower extremities, perianal numbness, urinary and fecal incontinence and impotence. Physical examination revealed decreased sensation in the S3, S4 and S5 dermatomes, a lax anal sphincter and bilateral leg weakness with absent deep tendon reflexes. A myelogram was normal however electromyographic studies showed acute denervation suggestive of a dorsal root ganglionitis and anterior horn cell myelitis, the etiology of which was uncertain. His condition steadily deteriorated with the development of drowsiness and confusion terminally. He died with clinical manifestations of bronchopneumonia and hemolytic anemia of uncertain origin.

At autopsy bronchopneumonia was confirmed in both cases. Case 1, however, also revealed malignant 'lymphoid' cells of $\mathrm{NAE}^{2}$ packing the small vessels of the brain (Figure 1), lungs, uterus, kidneys and adrenal glands with no parenchymal

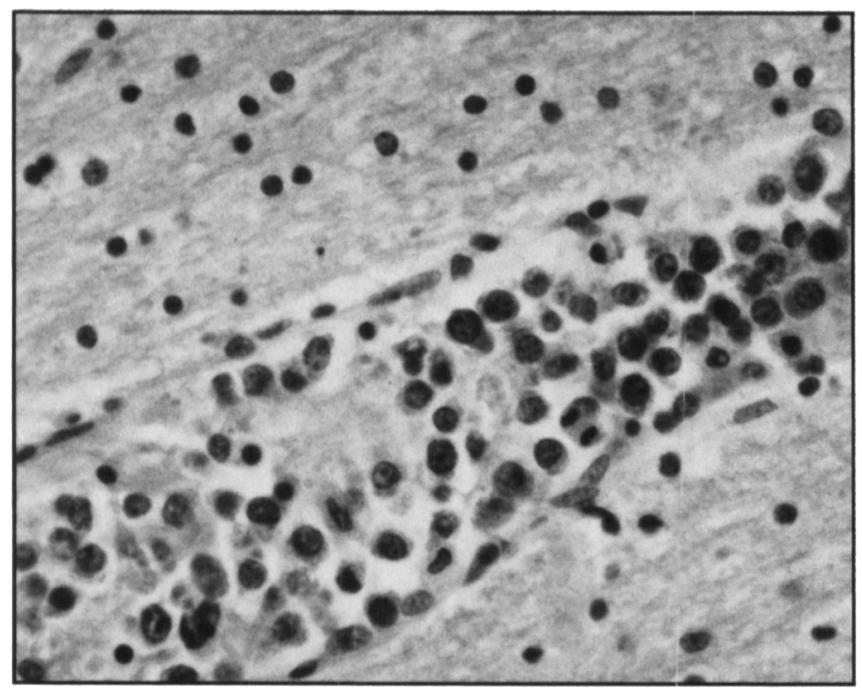

Figure I - Numerous malignant cells typical of NAE packing a small vessel in the brain. A mitotic figure is present in the centre. infiltration. Case 2 showed similar cells packing vessels within the spinal cord, heart, adrenal glands and brain, the latter with numerous small infarcts. In both cases there was no evidence of primary solid tumour, the blood films and bone marrow sections were unremarkable and in both the diagnosis had been clinically unsuspected.

NAE is controversial entity which now appears to be an angiocentric malignancy of lymphoid origin ${ }^{2-4}$ rather than the endothelial malignancy that was originally described. ${ }^{5}$ Endothelial markers such as Weibel-Palade bodies and Factor VIII antigen positivity are still occasionally cited ${ }^{5}$ although most recent cases have convincingly demonstrated lymphoid markers. ${ }^{2-4}$ The predilection of the malignant cells for central nervous system blood vessels is not understood however it does explain the variable neurological manifestations that occur. ${ }^{1-3}$

The two patients presented here demonstrate that clinical awareness of this entity must be increased in order to maximize the opportunity for adequate ante-mortem study with appropriate sampling and processing of tissues. Until this occurs the histogenetic origins of the malignant cells in NAE will remain obscure resulting in the continuance of the present unsatisfactory state where there are no treatment protocols for this interesting but highly lethal disease.

Roger W. Byard
Manual Orizaga
Department of Laboratory Medicine
Ottawa Civic Hospital and
University of Ottawa

\section{REFERENCES}

1. Shuaib A, Murphy WJ. Angioendotheliosis (NA): An elusive diagnosis. Can J Neurol Sci 1986; 13: 195

2. Wick MR, Mills SE, Scheithauer BW, Cooper PH, Davitz MA, Parkinson K. Reassessment of malignant "angioendotheliomatosis". Evidence in favour of its reclassification as "intravascular lymphomatosis". Am J Surg Path 1986; 2: 112-123.

3. Carroll TJ, Schelper RL, Goeken JA, Kemp JD. Neoplastic Angioendotheliomatosis: immunopathologic and morphologic evidence for intravascular malignant lymphomatosis. Am J Clin Path 1986; 85: 169-75.

4. Sheibani K, Battifora H, Winberg CD, Burke JS et al. Further evidence that "Malignant Angioendotheliomatosis" is an angiotropic large-cell lymphoma. N Engl J Med 1986; 314: 943-948.

5. Kitagawa M, Matsubara $O$, Song S-Y, Kurashima $C$, Okeda $R$, Kasuga T. Neoplastic angioendotheliosis. Immunohistochemical and electron microscopic findings in three cases. Cancer 1985; 56: 1134-43.

\section{LIGATION AND LITIGATION}

\section{To the Editor}

In reading the "methods" section of the paper by Raymond et al, Can J Neurosci 1986; 13: 214-20, we note the following error, "arterial branches were . . litigated". While litigation, unfortunately, is on the rise in North America, we suspect the word is "ligated". In attempts to modify the technique in our laboratory, we plan to have ligatures (hopefully no lawyers). 